\title{
Film-Forming Spray of Water-Soluble Chitosan Containing Liposome-Coated Human Epidermal Growth Factor for Wound Healing
}

\author{
Abd. Kakhar Umar ${ }^{1, * \mathbb{D}}$, Sriwidodo Sriwidodo ${ }^{1, *} \mathbb{( D}$, Iman Permana Maksum ${ }^{2}$ and Nasrul Wathoni ${ }^{1}(\mathbb{D}$ \\ 1 Department of Pharmaceutics and Pharmaceutical Technology, Faculty of Pharmacy, Universitas Padjadjaran, \\ Sumedang 45363, Indonesia; nasrul@unpad.ac.id \\ 2 Biochemistry Laboratory, Department of Chemistry, Faculty of Mathematics and Natural Science, \\ Universitas Padjadjaran, Sumedang 45363, Indonesia; ip_maksum@unpad.ac.id \\ * Correspondence: abd17002@mail.unpad.ac.id (A.K.U.); sriwidodo@unpad.ac.id (S.S.); \\ Tel.: +62-(22)-84288888 (A.K.U. \& S.S.)
}

Citation: Umar, A.K.; Sriwidodo, S.; Maksum, I.P.; Wathoni, N.

Film-Forming Spray of Water-Soluble Chitosan Containing Liposome-Coated Human Epidermal Growth Factor for Wound Healing. Molecules 2021, 26 , 5326. https://doi.org/10.3390/ molecules 26175326

Academic Editor: Katarína Valachová

Received: 2 August 2021

Accepted: 31 August 2021

Published: 2 September 2021

Publisher's Note: MDPI stays neutral with regard to jurisdictional claims in published maps and institutional affiliations.

Copyright: (C) 2021 by the authors Licensee MDPI, Basel, Switzerland. This article is an open access article distributed under the terms and conditions of the Creative Commons Attribution (CC BY) license (https:// creativecommons.org/licenses/by/ $4.0 /)$.

\begin{abstract}
Human epidermal growth factor (hEGF) has been known to have excellent wound-healing activity. However, direct application to the wound area can lead to low hEGF bioavailability due to protease enzymes or endocytosis. The use of liposomes as coatings and carriers can protect hEGF from degradation by enzymes, chemical reactions, and immune reactions. Sustained release using a matrix polymer can also keep the levels of hEGF in line with the treatment. Therefore, this study aimed to develop a film-forming spray of water-soluble chitosan (FFSWSC) containing hEGF-liposomes as a potential wound dressing. The hEGF-liposomes were prepared using the hydration film method, and the preparation of the FFSWSC was achieved by the ionic gelation method. The hydration film method produced hEGF-liposomes that were round and spread with a Z-average of $219.3 \mathrm{~nm}$ and encapsulation efficiency of $99.87 \%$, whereas the film-forming solution, which provided good sprayability, had a formula containing $2 \%$ WSC and $3 \%$ propylene glycol with a viscosity, spray angle, droplet size, spray weight, and occlusion factor of $21.94 \pm 0.05 \mathrm{mPa}$.s, $73.03 \pm 1.28^{\circ}, 54.25 \pm 13.33 \mu \mathrm{m}, 0.14 \pm 0.00 \mathrm{~g}$, and $14.57 \pm 3.41 \%$, respectively. The $\mathrm{pH}$, viscosity, and particle size of the FFSWSC containing hEGF-liposomes were stable during storage for a month in a climatic chamber $\left(40 \pm 2{ }^{\circ} \mathrm{C}, \mathrm{RH} 75 \pm 5 \%\right)$. A wound healing activity test on mice revealed that hEGF-liposomes in FFSWSC accelerated wound closure significantly, with a complete wound closure on day 6. Based on the findings, we concluded that FFSWSC containing hEGF-liposomes has the potential to be used as a wound dressing.
\end{abstract}

Keywords: human epidermal growth factor; soy lecithin liposome; water-soluble chitosan; film-forming spray

\section{Introduction}

Various types of growth factor hormones (GFs) have been known to have woundhealing activities [1,2]. In normal circumstances, when a wound occurs, the body responds in several stages, namely: hemostasis, inflammation, proliferation, and remodeling. At the proliferation stage, GFs are released to accelerate wound healing, including vascular endothelial growth factor (VEGF), fibroblast growth factor (FGF), and human epidermal growth factor (hEGF). Among these GFs, hEGF has a function that includes the role of all GFs, including accelerating the regeneration of keratinocyte cells, fibroblasts, and the vascular epithelium [3-5]. It has been reported that the healing of diabetic foot ulcers (DFU) with hEGF therapy was five weeks faster than conventional treatment [6]. Research conducted by Tsang et al. (2003) in 21 patients with $0.04 \%$ hEGF showed total wound closure after 12 weeks [7]. However, similar to other proteins and polypeptides, the stability of hEGF is poor. Several studies have shown that chronic wounds locally secrete the protease enzyme 
that breaks down hEGF, which can reduce the effectiveness of its treatment. The protection of hEGF from these proteolytic enzymes has been investigated using antiproteolytic agents. It has been shown to increase the efficacy of hEGF in accelerating wound healing. However, this agent also significantly influences systemic enzymatic metabolism through topical administration [8].

In addition to antiproteolytic agents, the coating method using liposomes can also improve the in vivo stability of drugs. Lipid bilayers in liposomes prevent enzymatic degradation, immune reactions, and chemical interactions [9]. It has been reported that liposome-coated hEGF was more effective at healing wounds than hEGF itself [3]. Increased stability and localized delivery of hEGF in the injured area has also been reported to be better with liposome coating [10-15]. Due to its low stability, hEGF with immediate release will also only last for a short time. It has been reported that $60 \%$ of hEGF disappears within two hours after administration, which is most likely caused by earlier enzymatic degradation or the mechanism of receptor-mediated endocytosis [16]. One way to deal with these problems is through sustained release using a matrix, such as a film-forming spray preparation, which can increase the bioavailability of drugs with a low incidence of irritation compared to other conventional topical dosage forms. The application of a film-forming spray to the skin is also more comfortable, with a more uniform distribution of the drug that forms a thin film following the texture of the skin or wound [17,18]. A filmforming spray must be prepared using polymers that are viscoelastic or have in situ film properties. One of the natural polymers that can form films in situ is chitosan, which has been proven to be an efficient drug carrier for wound-healing therapy due to its excellent mucoadhesive properties, and its antimicrobial and antioxidant activities [19].

Previous studies of hEGF-liposomes in acid-soluble chitosan hydrogels were investigated by Degim et al., who found that hEGF could be stable and last for a long period of time in the wound area $[15,20]$. However, the use of acids to dilute chitosan can produce distinctive aromas that are uncomfortable and can irritate wound mucosal tissue [21]. The application of hydrogel preparations also allows cross-infection, nonuniform dosage, and uneven drug distribution [22]. Therefore, we developed a film-forming spray using water-soluble chitosan containing hEGF-liposomes as a potential preparation for wound healing. In this study, we characterized the physicochemical properties, encapsulation efficiency, and sprayability of the film-forming spray of water-soluble chitosan (FFSWSC) containing hEGF-liposomes, and evaluated its effectiveness in healing wounds in mice.

\section{Result}

\subsection{Excipient Optimization and the Preparation of Film-Forming Solutions}

Film-forming solutions produced using 1\% CAS and 1\% CWS had a clear yellow color, but the CAS has a sharp acetic acid aroma with a thicker consistency and was difficult to spray. Therefore, water-soluble chitosan was chosen as the basis for the filmforming solution. The CWS concentration was raised because it produced a rigid film and easily cracked at a level of $1 \%$, while CWS was difficult to spray at a concentration of $4 \%$. Therefore, the optimization was carried out at concentrations of $2 \%$ and $3 \%$. Figure 1 shows the physical appearance of the optimized film-forming base solutions.

The use of benzoic acid in the CWS solution resulted in white particles that were not dissolved at the bottom of the solution. The solubility of benzoic acid in aqueous solution is indeed very low [23]. With the use of methylparaben, blackening occurred after 40 days of storage at room temperature (Figure 2, left), while the base solution using the sodium benzoate preservative did not show significant physical changes. This phenomenon might have been caused by the interaction between methylparaben and tween 80. Therefore, the activity of methylparaben as a preservative decreased, and resulted in a growth of microorganisms $[24,25]$. The use of PG $>10 \%$ can prevent interactions between methylparaben and tween 80 [26,27]. However, the film-forming solution had poor sprayability and prolonged film-drying time, so the PG concentration used was less than $10 \%$. 


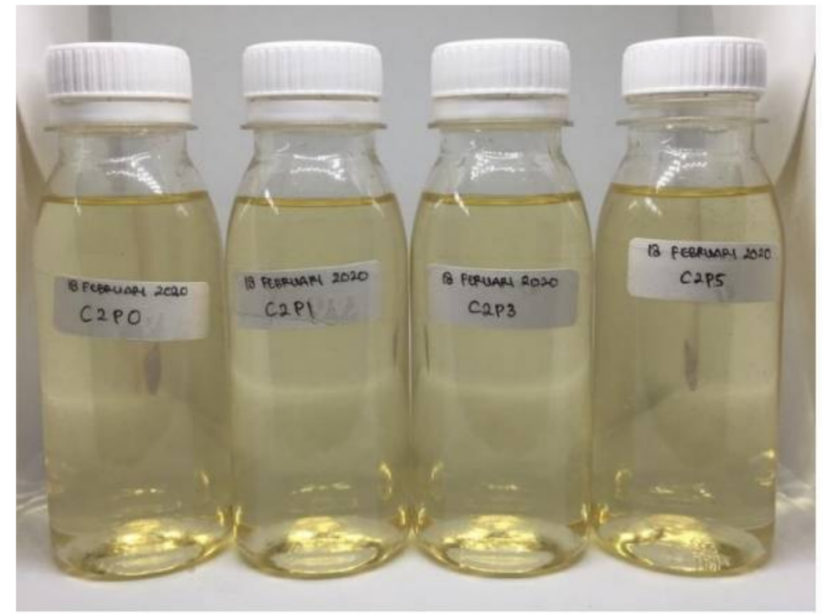

A

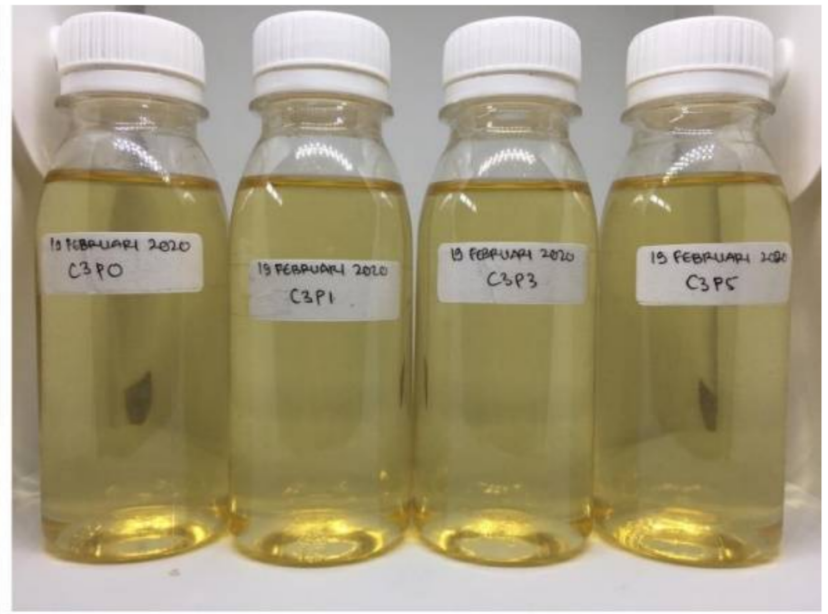

B

Figure 1. CWS $2 \%$ (A) and 3\% (B) film-forming solutions using propylene glycol as the plasticizer.

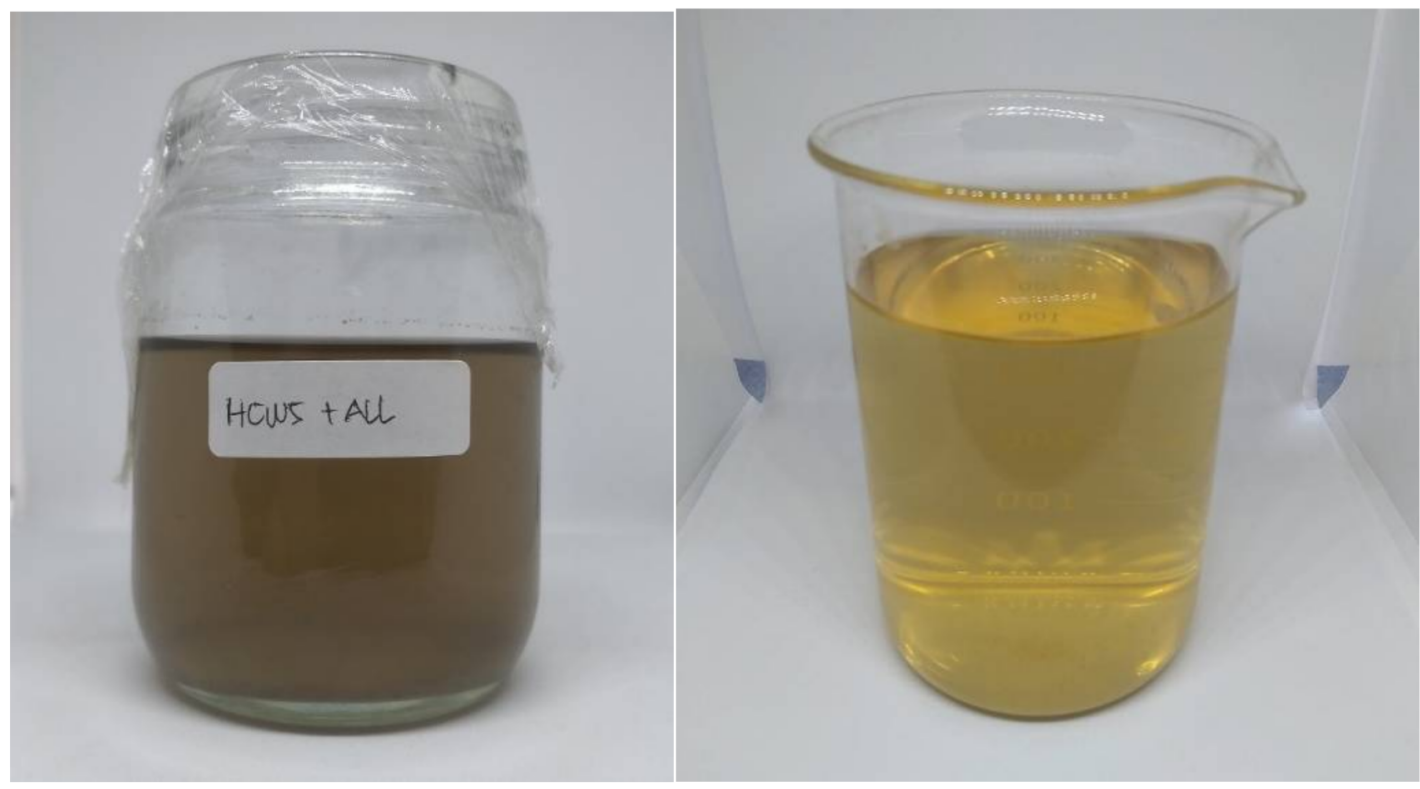

Figure 2. The film-forming solution containing methylparaben (left) and sodium benzoate (right).

The use of glycerin as a plasticizer provided a significant increase in viscosity of the film-forming solution compared to PG. The drying time was also longer than for PG. Therefore, the optimization was continued using PG as a plasticizer and sodium benzoate as a preservative. The optimized formula can be seen in Table 1.

Table 1. The optimized formulas.

\begin{tabular}{ccccc}
\hline \multirow{2}{*}{ Formula } & \multicolumn{3}{c}{ Excipient (\%) } \\
\cline { 2 - 5 } & Chitosan & Propylene Glycol & Tween 80 & Sodium Benzoate \\
\hline C2P0 & 2 & 0 & 2 & 0.1 \\
C2P1 & 2 & 1 & 2 & 0.1 \\
C2P3 & 2 & 3 & 2 & 0.1 \\
C2P5 & 2 & 5 & 2 & 0.1 \\
C3P0 & 3 & 0 & 2 & 0.1 \\
C3P1 & 3 & 1 & 2 & 0.1 \\
C3P3 & 3 & 3 & 2 & 0.1 \\
C3P5 & 3 & 5 & & 0.1 \\
\hline
\end{tabular}




\subsection{Preparation of hEGF-Liposomes}

Lecithin and cholesterol were mixed into the chloroform:methanol (1:1) solvent to produce a mixture that dissolved and had the color of soy lecithin (like honey). As the mixture was stirred, the mixture developed a thicker consistency with a fading, paler color of lecithin. The mixture also had a bubbly texture. Therefore, the surface morphology of the lecithin-cholesterol film was observed using a digital microscope to confirm this phenomenon.

Then, the lecithin-cholesterol film that had dried was moistened with PBS pH 7.4, producing a yellowish-white suspension. The physical appearance of the liposome suspension obtained was similar to that obtained by Shashidar and Manohar [28], who also used soy lecithin as a source of phospholipids. The suspension was then immediately prepared for particle measurement and partly dried in a petri dish at room temperature for FTIR analysis.

\subsection{Entrapment Efficiency}

Based on the measurement results, a 99.87\% entrapment efficiency of liposomes was found with a drug loading of $2 \%$. This indicated that the liposomes had successfully coated the hEGF with a high entrapment efficiency. Further evidence was found through TEM observations and the therapeutic effectiveness.

\subsection{Measurement of Viscosity and $\mathrm{pH}$}

The measurement results showed that the increase in chitosan concentration significantly affected its sprayability (spray angle and droplet size). It was found that a level of CWS of 3\% with the highest concentration of propylene glycol (5\%) resulted in a spray diameter that began to shrink $(5.74 \pm 0.26 \mathrm{~cm})$ with a spray angle of $79.17 \pm 0.48$. This phenomenon showed that the optimal limit of viscosity to produce good sprayability was below $50 \mathrm{mPa}$.s. Ranade et al. [29] also confirmed that good sprayability was in the range of 25 to $45 \mathrm{mPa}$.s; this was shown at a CWS level of $4 \%$, which produced a viscosity of $77.0 \mathrm{mPa}$.s with a centralized spray without spreading droplets, while the $\mathrm{pH}$ of chitosan ranged between $3.9 \pm 0.1$ and $4.4 \pm 0.1$.

\subsection{Observation of hEGF-Liposome FTIR Spectrum}

Observation of the FTIR spectrum between hEGF and liposomes aimed to determine whether there was an interaction in the encapsulation of hEGF. The hEGF spectrum produced peaks at 3400, 3285, 2943, 2895, 1648, 1425, 1281, 1080, 1019, 930, 882, 698, 630, and $587 \mathrm{~cm}^{-1}$; whereas liposomes had peaks at 3738, 3418, 3020, 2930, 2860, 2380, 1745, 1468, 1380, 1240, 1175, 1060, and $672 \mathrm{~cm}^{-1}$. The FTIR spectrum of the hEGF-liposomes had a peak that is also found in the liposomes and hEGF itself (Figure 3). There were no unique peaks in the hEGF-liposome FTIR spectrum, which indicated that there was no formation of new covalent bonds in the encapsulation process. This phenomenon indicated that the release of hEGF from the liposomes was more efficient at the target site [28].

In the FTIR liposome spectrum, there was a peak at $3418 \mathrm{~cm}^{-1}$, indicating the presence of hydrogen bonds, which are the main character in macromolecular interactions such as those of phospholipids [30]. The peaks at 1240 and $1745 \mathrm{~cm}^{-1}$ were the corresponding peaks for the phosphate $(\mathrm{P}=\mathrm{O})$ and ester $(\mathrm{C}=\mathrm{O})$ groups on the polar head of phospholipids [31]. Aliphatic chains were also clearly seen at the peaks of 2930 and $2860 \mathrm{~cm}^{-1}$, followed by peaks at $1468 \mathrm{~cm}^{-1}$, which indicated the hydrophobic tail chain of phospholipids. 


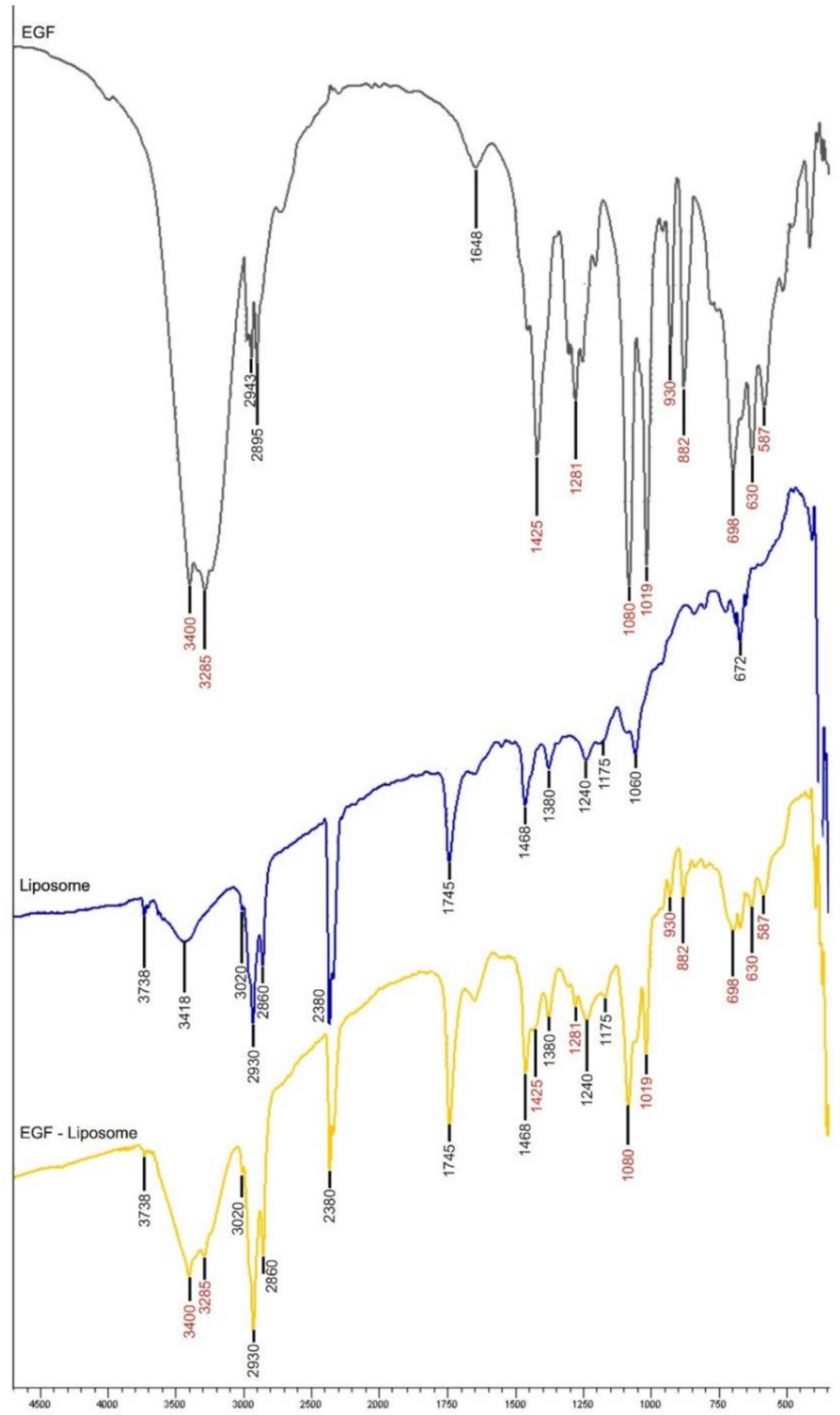

Figure 3. FTIR spectra of hEGF (black), liposomes (blue), and hEGF-liposomes (yellow) that did not show the presence of new covalent bonds in the encapsulation process.

\subsection{Determination of the Deacetylation Degree of Chitosan}

The \%DD data from chitosan were used to confirm its relationship with the characteristics of the preparation. It was reported that high \%DD could improve mechanical strength and the ability to absorb moisture from chitosan [32]. Based on the FTIR spectrum obtained (see Figure 4), the absorbance value was obtained by converting the transmittance value using the formula $\mathrm{A}=2-\log (\% \mathrm{~T})$ so that $\mathrm{A}_{1320}=0.240 ; \mathrm{A}_{1420}=0.248 ;$ and $\% \mathrm{DD}=81.31 \%$. 


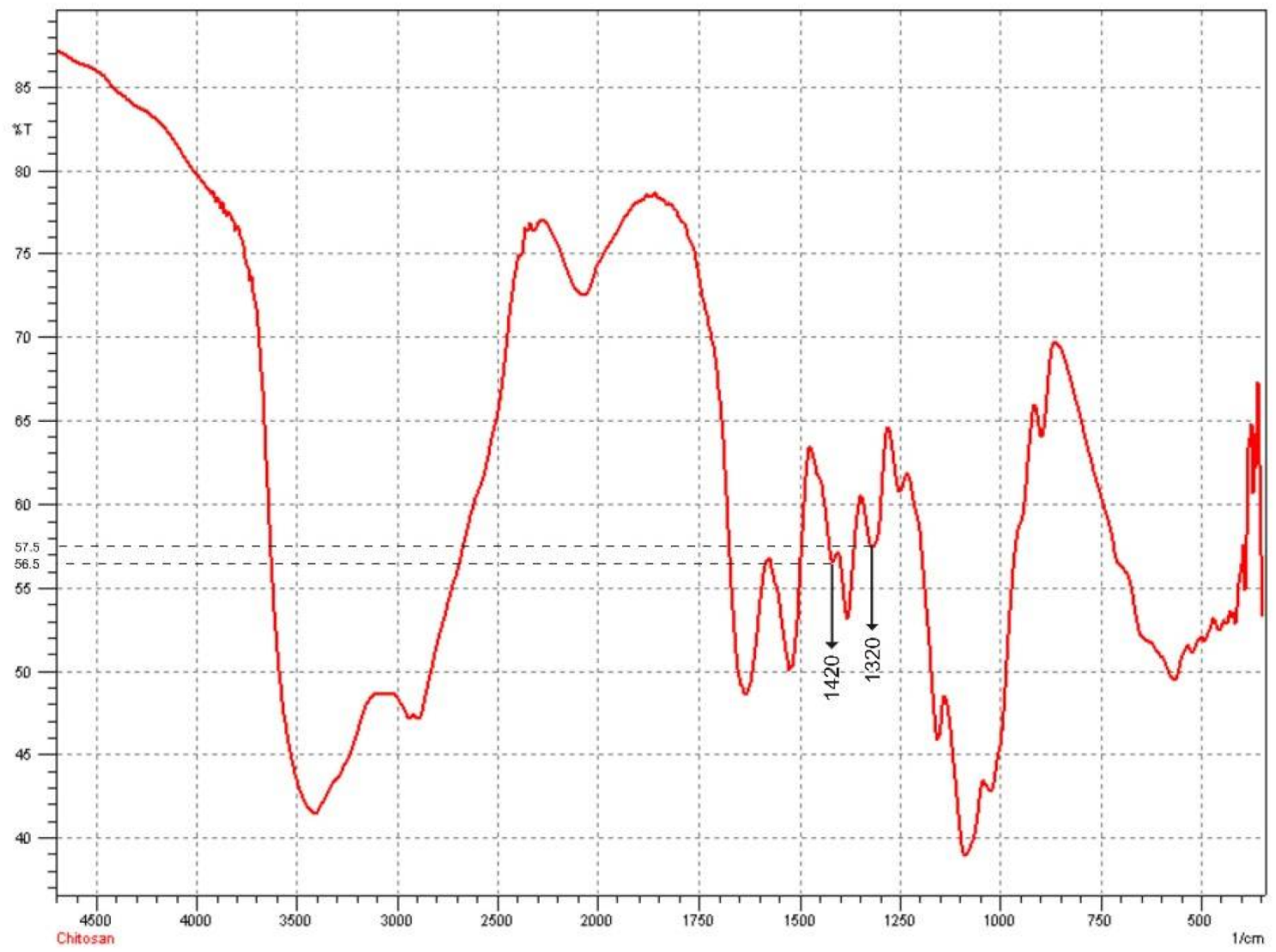

Figure 4. FTIR spectra of chitosan.

\subsection{Determination of Particle Size, Polydispersity Index, and Zeta Potential}

Different sonication processes produced different particle sizes. Sonication using a probe sonicator (cycle of 0.5 and amplitude of 70\%) (Hielscher UP200S, Hielscher Ultrasonics $\mathrm{GmbH}$, Teltow, Germany) produced a smaller particle size of the blank liposomes at the highest volume $(16 \%)$, which was $64 \mathrm{~nm}$, whereas the sonication bath process produced a larger size of $219.3 \mathrm{~nm}$ (see Table 2).

Table 2. The value of z-average, polydispersity index, and zeta potential.

\begin{tabular}{cccc}
\hline Figure & Z-Average $(\mathbf{n m})$ & Polydispersity Index & Zeta Potential (mV) \\
\hline Empty liposome & 64 & 0.34 & - \\
\hline Empty liposome & 338.9 & 0.41 & -57.3 \\
\hline hEGF-liposome & 219.3 & 0.22 & -39.7 \\
\hline Empty liposome KIT & 341.0 & 0.50 & 12.8 \\
\hline hEGF-liposome KIT & 853.8 & 0.66 & 25.8 \\
\hline
\end{tabular}

Note: all liposomes were prepared using a bath sonicator, except that marked with $\left(^{*}\right)$.

At the PDI value, the value that meets the requirements for lipid nanocarrier is below 0.3 . Values above 0.7 indicate a very broad or inhomogeneous particle distribution [33]. In Table 2, it can be seen that the PDI values of the hEGF-liposomes indicated the uniformity of particle size distributions that met the requirements.

In Figure 5, it can be seen that KIT liposomes tended to be less stable, and formed aggregates. This was marked by the appearance of two peaks, one of which was nanosized, while the other was microsized. Microsized peaks were for a result of the aggregate size of the liposomes [34], whereas in the test liposome, only one peak was formed, and indicated 
that the dispersion was more stable than the KIT liposome. This was also supported by potential zeta data (see Table 2), where ethical zeta potential values ranged between \pm 30 and $\pm 60[35]$.

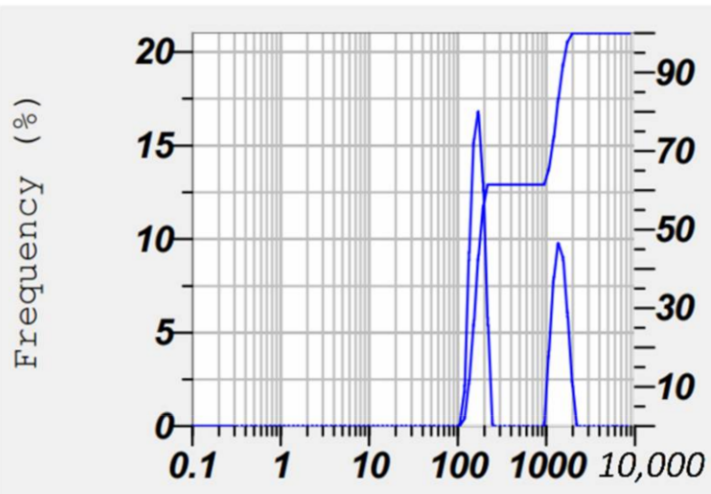

A

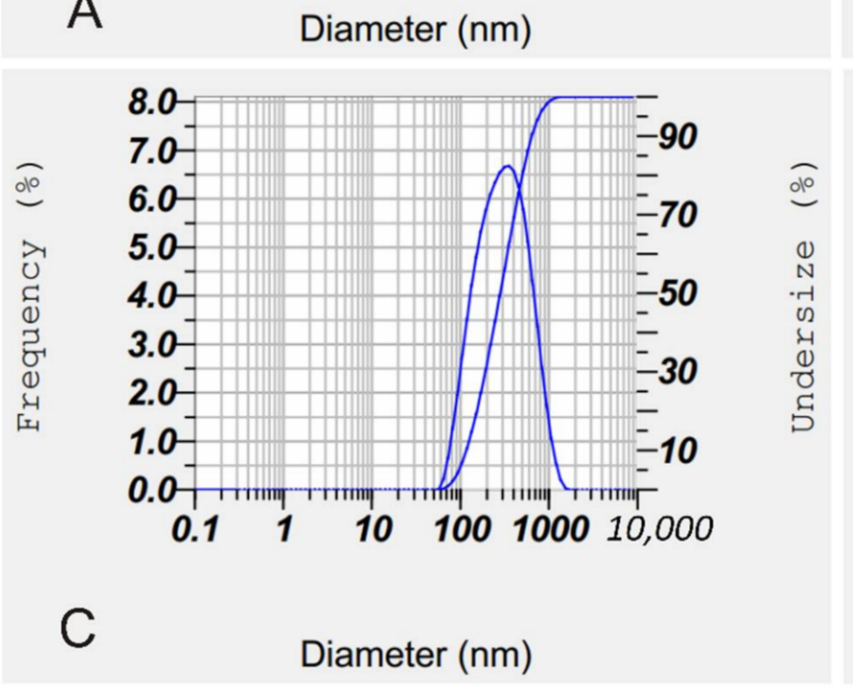

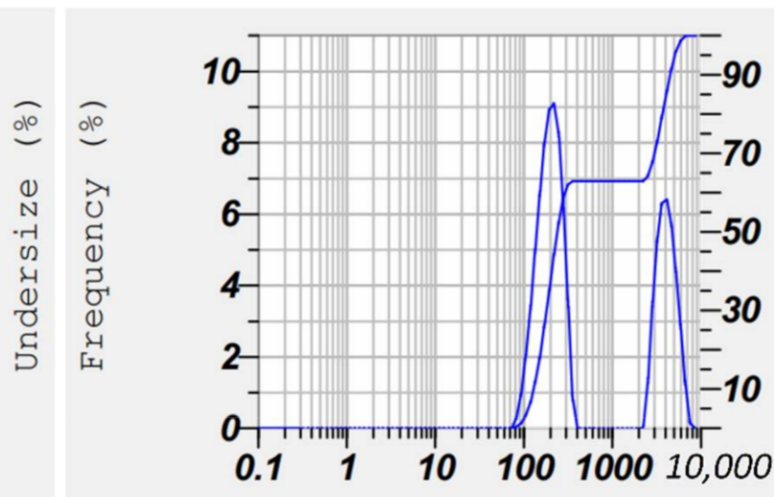

B

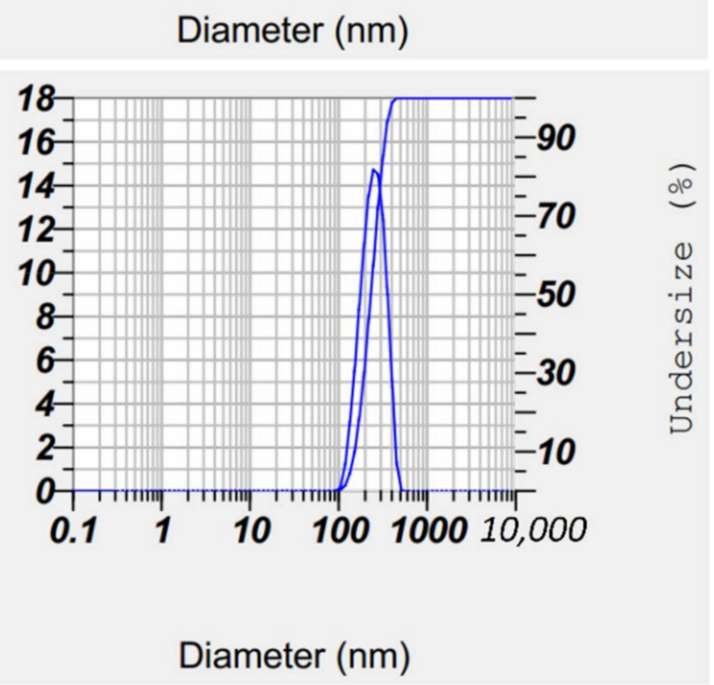

Figure 5. Graph of particle size of blank liposome KIT (A), hEGF-liposome KIT (B), blank liposomes test (C), and hEGFliposome tests (D).

\subsection{Observation of hEGF-Liposome Surface Morphology and TEM Analysis}

Morphological observations using a digital microscope at $1000 \times$ magnification confirmed the presence of bubbles that were absorbed in the mixture of lecithin and cholesterol during physical mixing (Figure 6). The stirring process was carried out slowly, but still produced a bubbly texture. This phenomenon showed the natural tendency of phospholipids to form vesicle structures in reaching thermodynamic equilibrium, which may be initiated by the humidity of the surrounding environment and the water content in the solvent (methanol) [36].

With the same preparation procedure, the test liposome and the KIT liposome were compared using TEM to observe the shape and the coating ability of hEGF. In Figure 7, it can be seen that the shape of the test liposome was more rounded (see Figure 7C), with a smaller size than the KIT liposome (see Figure 7A). Dispersions between KIT liposome particles were also close together, and its hEGF coating tended to form aggregates (see Figure $7 \mathrm{~B}, \mathrm{D})$. 


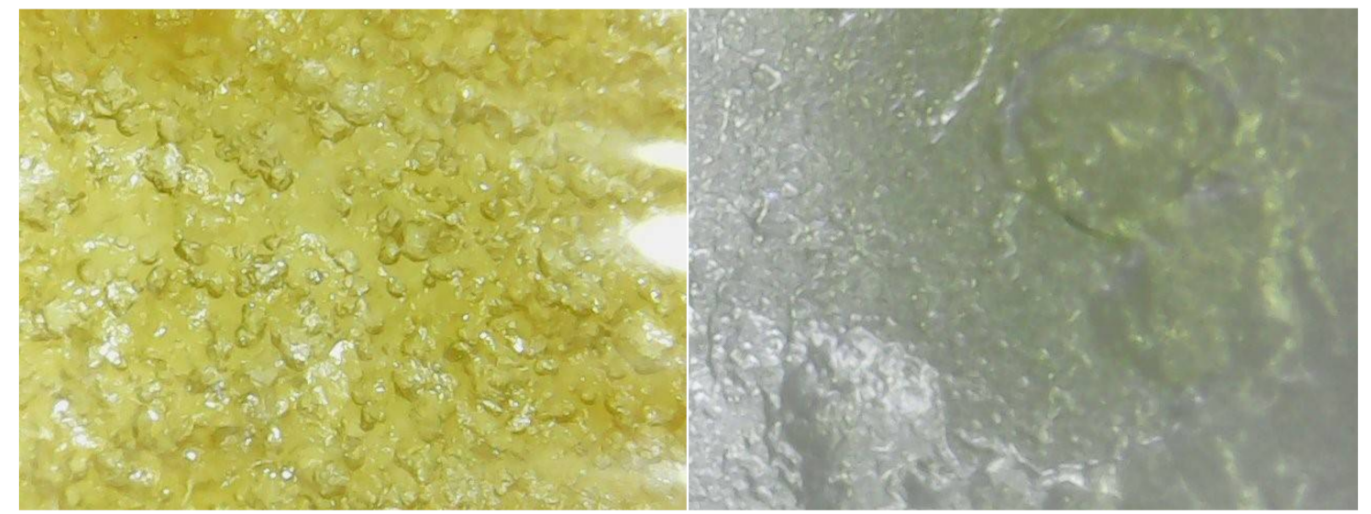

Figure 6. Observation of surface morphology using a digital USB microscope. Film of lecithincholesterol before being hydrated (left); hydrated hEGF-liposome film (right).
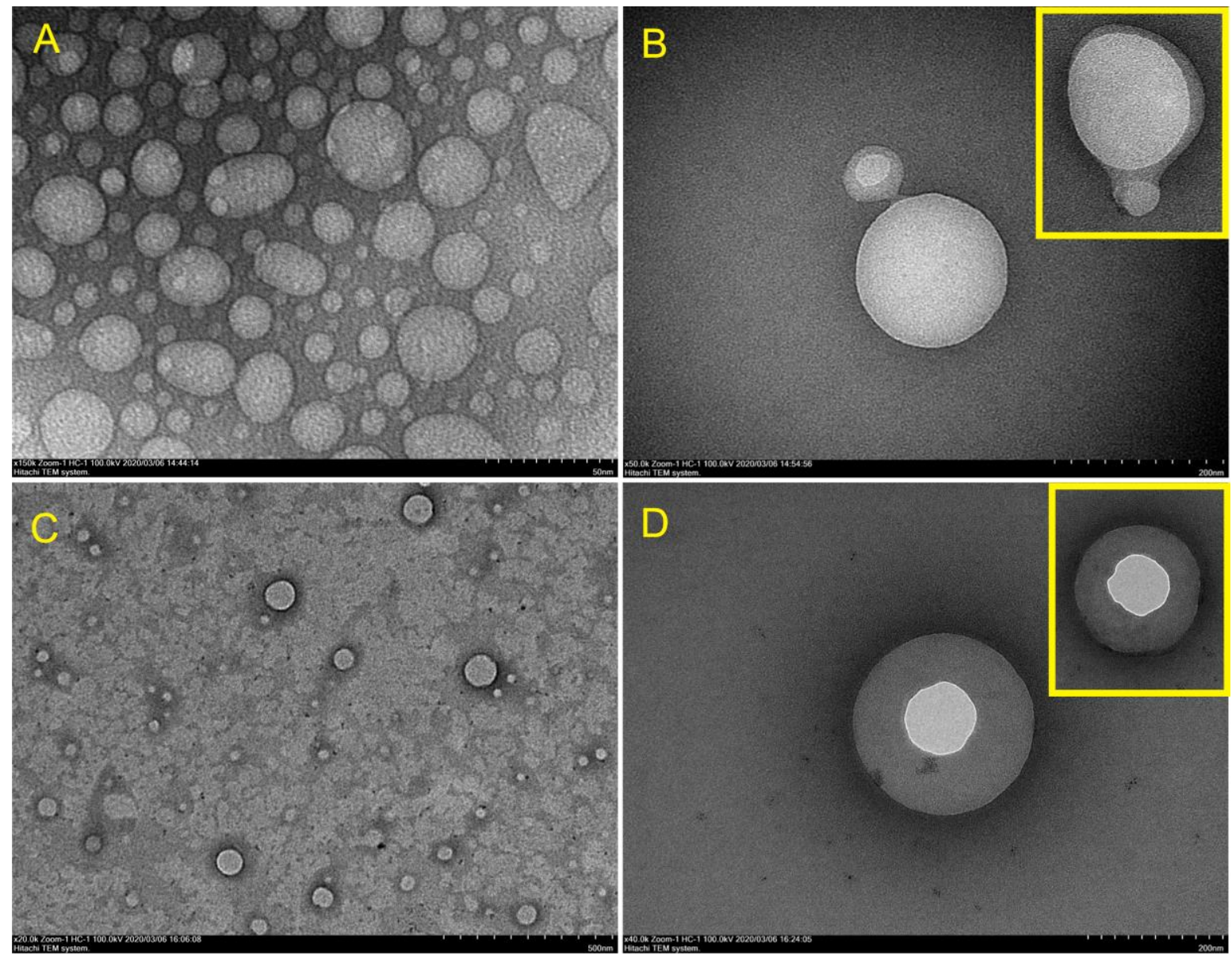

Figure 7. Shape observation using TEM: (A) empty KIT liposomes; (B) hEGF-liposome KIT; (C) empty test liposomes; (D) hEGF-liposome tests.

In contrast to the KIT liposome, the dispersed test liposome was more spaced, and formed a more rounded and stable coating. TEM observations also confirmed the results of particle size measurements using PSA that the particle size of the hEGF-liposome test ranged from $200-300 \mathrm{~nm}$.

\subsection{Occlusion Potential of Film}

Occlusion factors describe a film's permeability to water vapor. The smaller the occlusivity factor value, the better the permeability of the film to water vapor [29]. In this 
test, it was seen that an increase in CWS concentration correlated with an increase in the occlusivity factor $(\alpha=0.47 ; p \leq 0.05)$. Research conducted by Zhuang (2019) showed that the permeability of chitosan films to water vapor increased at $\% \mathrm{DD}>81.0 \%$ [37], and the chitosan used in this study had a $\%$ DD of $81.31 \%$. Formulas that produce good water permeability contain $2 \%$ CWS.

\subsection{Spray Angle, Pattern, and Droplet Size Distribution}

Each spray produced a different spray pattern depending on the pattern of holes in the nozzle, but still produced a good spread. Spray angle showed the spread of spray from the film-forming solution. A good spray angle is below $85^{\circ}[38,39]$. The average spray angle formed ranged between $73.03 \pm 1.96$ and $79.17 \pm 0.48$ (see Table 3). Increasing the CWS concentration had a significant effect on increasing spray angle $(\alpha=0.67 ; p<0.01)$ and also on increasing droplet size $(\alpha=0.39 ; p<0.05)$. As previously explained, the viscosity of the solution greatly influenced the sprayability, and CWS had a greater role than propylene glycol in increasing viscosity. Statistical analysis also showed that the increase in propylene glycol concentration did not have a significant impact on increasing the spray angle and droplet size. Based on this test, the C2P3 formula showed the best results, which had the lowest spray angle and droplet size, with values of $73.03 \pm 1.28^{\circ}$ and $54.25 \pm 13.34 \mu \mathrm{m}$, respectively.

Table 3. Average values of measurements of viscosity, $\mathrm{pH}$, spray angle, droplet size, and spray weight.

\begin{tabular}{cccccccc}
\hline Formula & $\begin{array}{c}\text { Viscosity } \\
(\mathbf{m P a . s})\end{array}$ & $\mathbf{p H}$ & $\begin{array}{c}\text { Spray Angle } \\
(\boldsymbol{\theta})\end{array}$ & $\begin{array}{c}\text { Droplet Size } \\
(\boldsymbol{\mu m})\end{array}$ & $\begin{array}{c}\text { Spray Weight } \\
(\mathbf{g})\end{array}$ & $\begin{array}{c}\text { Occlusion Factor } \\
(\mathbf{\%})\end{array}$ \\
\hline C2P0 & $20.90 \pm 0.06$ & $4.3 \pm 0.1$ & $74.67 \pm 1.96$ & $92.90 \pm 14.10$ & $0.14 \pm 0.00$ & $12.44 \pm 2.97$ \\
\hline C2P1 & $21.00 \pm 0.00$ & $4.4 \pm 0.1$ & $77.05 \pm 0.85$ & $88.90 \pm 46.04$ & $0.15 \pm 0.00$ & $14.44 \pm 5.26$ \\
\hline C2P3 & $21.94 \pm 0.05$ & $4.2 \pm 0.1$ & $73.03 \pm 1.28$ & $54.25 \pm 13.34$ & $0.14 \pm 0.00$ & $14.57 \pm 3.41$ \\
\hline C2P5 & $23.46 \pm 0.23$ & $4.2 \pm 0.1$ & $75.51 \pm 1.94$ & $69.07 \pm 12.05$ & $0.14 \pm 0.00$ & $19.69 \pm 3.79$ \\
\hline C3P0 & $52.00 \pm 0.00$ & $3.9 \pm 0.1$ & $76.90 \pm 0.84$ & $82.55 \pm 22.44$ & $0.14 \pm 0.00$ & $25.26 \pm 4.11$ \\
\hline C3P1 & $53.18 \pm 0.26$ & $4.0 \pm 0.1$ & $77.87 \pm 0.71$ & $112.82 \pm 44.70$ & $0.13 \pm 0.00$ & $22.93 \pm 4.42$ \\
\hline C3P3 & $55.12 \pm 0.24$ & $4.0 \pm 0.1$ & $77.74 \pm 0.83$ & $117.15 \pm 14.60$ & $0.14 \pm 0.00$ & $22.28 \pm 3.03$ \\
\hline C3P5 & $56.20 \pm 0.24$ & $3.9 \pm 0.1$ & $79.17 \pm 0.48$ & $84.29 \pm 37.44$ & $0.14 \pm 0.00$ & $20.47 \pm 1.46$ \\
\hline
\end{tabular}

Note: All tests were repeated five times, except those marked with $\left({ }^{*}\right)$, which had three repetitions.

\subsection{Uniformity of Weight per Spray}

Spray weights on all optimized formulas produced excellent uniformity, with an average weight of $0.14 \pm 0.00 \mathrm{~g}$ to $0.15 \pm 0.00 \mathrm{~g}$, which indicated that the sprayer used could produce a uniform dose. Statistically, an increase in propylene glycol concentration showed a correlation with a decrease in spray weight $(\alpha=0.33 ; p<0.05)$.

When viewing all the test parameters (see Table 3), formulas containing $2 \%$ CWS and $3 \%$ PG (C2P3) produced the best film-forming spray characteristics, with the lowest spray angle and droplet size $\left(73.03 \pm 1.28^{\circ}\right.$ and $\left.54.25 \pm 13.338 \mu \mathrm{m}\right)$ and the best spray weight uniformity.

\subsection{Drying Shrinkage of the Film-Forming Solution}

The test results showed that the film-forming solution of chitosan shrunk with a constant ratio for each volume to form a film; this was marked by the $\mathrm{R}^{2}$ value, which was equal to 1 . These data can be used to predict the mass of the film that will be formed from the volume of the film-forming solution, which could be useful in planning industrial manufacturing and determining the dosage of drugs per unit mass of film. 


\subsection{Theoritical Film Thickness}

The chitosan film (C2P3 formula) had a density of $1.04 \mathrm{~g} / \mathrm{cm}^{3}$, an average film area of $65.86 \pm 0.42 \mathrm{~cm}^{2}$, and an average spray weight of $0.14 \pm 0.004 \mathrm{~g}$. Based on these data, the film thickness formed by spraying was about $0.002 \mathrm{~cm}$, or 20 microns.

\subsection{Stability Test}

The one-month stability test was carried out by storing the preparation in a climatic chamber in zone IVB conditions. During the test, there was no significant change in $\mathrm{pH}$ and viscosity (see Table 4). The particle size (about $200 \mathrm{~nm}$ ) also did not change significantly. The PDI value changed from 0.22 to 0.26 , but was still acceptable for a lipid nanocarrier (below 0.3) [33].

Table 4. Stability data for the film-forming spray of water-soluble chitosan containing hEGFliposomes.

\begin{tabular}{ccccc}
\hline Day & $\mathbf{p H}$ & Viscosity (mPa.s) & Particle Size $(\mathbf{n m})$ & PDI \\
\hline 0 & $4.24 \pm 0.05$ & $21.94 \pm 0.05$ & 219.3 & 0.219 \\
1 & $4.24 \pm 0.05$ & $21.74 \pm 0.05$ & - & - \\
7 & $4.26 \pm 0.05$ & $21.62 \pm 0.16$ & - & - \\
14 & $4.22 \pm 0.05$ & $21.60 \pm 0.14$ & - & - \\
28 & $4.24 \pm 0.05$ & $21.58 \pm 0.13$ & 207.9 & 0.260 \\
\hline
\end{tabular}

\subsection{In Vivo Study}

A wound-healing effectiveness test was aimed seat observing the effect of the active substance coating system and continuous release through film formation by chitosan on the rate of wound healing. The effectiveness between hEGF KIT and recombinant hEGF produced in the previous study was also compared in this study [40]. Based on the test results, it was found that group 6 had a significant rate of wound closure compared to all other groups, with wound closure reaching $91.671 \%$ on day 4 . On day 4 , groups 2,4 , and 5 showed a significant difference in wound closure compared to the control group. Group 5 also has a significant difference from group 2 . This showed that hEGF and chitosan had natural wound-healing activity, and that coating hEGF using liposomes can increase the hEGF's effectiveness. On day 6 , the wounds in group 6 had closed completely, with a significant difference from all groups except in group 5 . All groups showed a significant difference from the control group, with a percentage of wound closure in groups 2, 3, 4, 5 , and 6 of $75.885 \%, 77.288 \%, 81.958 \%, 89.115 \%$, and $100 \%$, respectively. The other group achieved $100 \%$ wound closure on day 8 and above. This assay showed that hEGF could be more effective through coating with liposomes, and was significantly affected by the control of hEGF release by chitosan. The effectiveness of recombinant hEGF also appeared to be better than hEGF KIT, although not statistically significant (see Figure 8). 


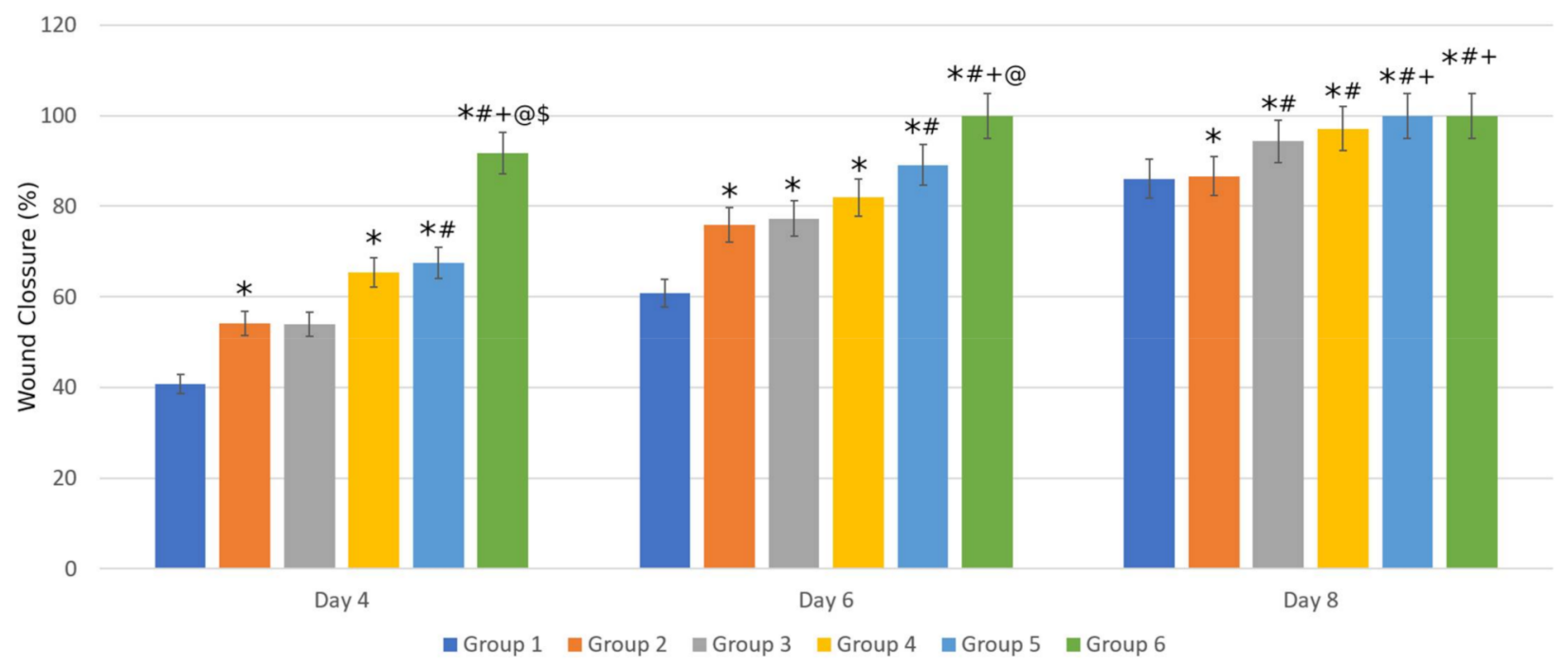

Figure 8. Wound closure percentage of each group and the significance of the differences analyzed using Games-Howell and Bonferroni post hoc tests. Note: $\left({ }^{*}, p<0.05\right)$ shows a significant difference to group 1 . (\#, $\left.p<0.05\right)$ shows a significant difference to group 2. $(+, p<0.05)$ shows a significant difference to group 3. (@, $p<0.05)$ shows a significant difference to group 4. $(\$, p<0.05)$ shows a significant difference to group 5 .

\section{Discussion}

The nature of the excipient used greatly determines the sprayability of a mixture. Ingredients that affect the viscosity and flow properties of the mixture need to be optimized to obtain the best formula. In this study, the effect of chitosan and PG on the sprayability of the mixture was studied. CWS at $2 \%$ and PG at $3 \%$ produced the most optimal spray angle, droplet size, spray weight uniformity, and occlusion factor. CWS concentration played an important role in determining the spray angle and droplet size, while PG affected the flow properties of CWS so that it reduced the spray weight uniformity. This was certainly not related to viscosity, because there was no significant difference in the spray weights of $2 \%$ and $3 \%$ CWS, while the viscosity was quite different. Chitosan is known to have thixotropic flow properties that can become more fluid when stressed, and can return to its original consistency after the stress is removed [41,42]. However, PG is reported to have a large influence on the nature of chitosan flow [43]. PG is also known to increase the stickiness and friability of chitosan films at 5\% PG [39,44].

Sonication using a probe sonicator produced physical changes, with slowly blackened hEGF-liposome dispersion. This phenomenon may have been due to the high temperature generated by the probe sonicator, which can degrade hEGF $[25,26]$. In addition, using a probe sonicator for an extended period of time can cause the lipids to become de-esterified, and titanium on the probe can slough off and pollute the solution [27]. Therefore, the sonication process was carried out using a bath sonicator. A non-titanium probe sonicator with temperature controller may be suitable. In Table 2, it can be seen that the particle size of the hEGF-liposomes was smaller than that of the empty liposomes. In several studies, a decrease in liposome size was also shown after exposure to drugs or protein [45-47]. According to the Derjaguin-Landau-Verwey-Overbeek (DLVO) theory, this decrease in size can be caused by osmotic pressure, in which water is evacuated from the liposome nucleus due to changes in the difference in solute concentrations in the system and the liposome nucleus [47-49]. The size of the liposome KIT was also larger than the test liposome. This phenomenon could be influenced by the surface charge of the liposome, where ionic liposomes generally have a smaller size compared to neutral liposomes [46]. Based on the potential zeta value, it can be seen that the test liposome had a negative charge, while the KIT liposome had no charge (neutral). The zeta potential value obtained was also influenced by the use of tween 80 as a surfactant. This surfactant also played a role in maintaining the stability of the liposome dispersion. 
The application of liposomes as an hEGF coating aimed to protect the hEGF from protease degradation. In this study, liposome-coated hEGF showed a better acceleration of wound healing than uncoated hEGF, although not statistically significant. In this assay, the group of mice treated with liposome-coated hEGF showed complete wound closure on day 8 , while the group given uncoated hEGF showed complete wound closure on day 10 and above. Although liposome-coated hEGF had faster wound closure than without coating, continuous release control was still required to prevent receptor mediated endocytosis.

In this study, chitosan played a role in regulating sprayability, and also formed a thin film matrix to regulate hEGF release. This role was important to keep hEGF levels continuously available to provide a sustainable therapeutic effect. Based on the in vivo test results, it could be seen that the administration of liposome-coated hEGF in a chitosan base significantly increased the rate of wound closure compared to other groups, with complete closure on day 6 . In addition, the group that was given chitosan (groups 2 and 6) showed different characteristics of wound closure. Groups 2 and 6 tended to form scabs on the wound tissue, so that the wound became dry and closed quickly (see Figure 9). Scabs are said to be beneficial because they can prevent blood loss and infection. In addition, the scab also prevents exposure to ultraviolet radiation well [46]. Scabs in group 6 also did not appear to leave scars, and even the scar areas in some mice had regrown hair by day 9. Based on the test results, we concluded that liposome coating can increase the woundhealing activity of hEGF through protection against protease degradation and continuous release of chitosan, providing optimal levels of hEGF in the wound area constantly.

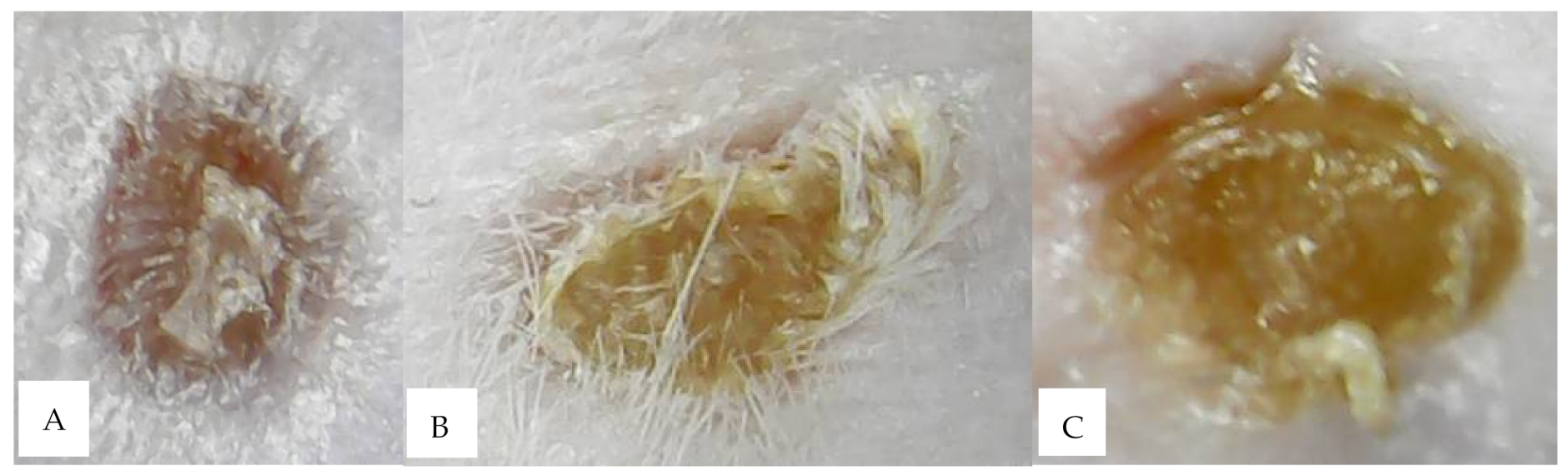

Figure 9. The different wound textures of the three groups: (A) hEGF-liposome; (B) hEGF-liposome-base; (C) base group.

\section{Material and Methods}

\subsection{Materials}

We used acid-soluble chitosan (CAS) (food and medical grade with a deacetylation degree of $>90 \%$, made of crab shell or shrimp shell, Bio Chitosan, Indonesia), water-soluble chitosan (CWS) (food and medical grade with a deacetylation degree of $>90 \%$, made of crab shell or shrimp shell, Bio Chitosan, Indonesia), hEGF obtained from recombinant results from previous studies [40], soy lecithin (food and medical grade, Lansida, PT. Saraswanti Indo Genetech, Indonesia), cholesterol monohydrate (sigma grade with purity of $\geq 99 \%$, made of sheep wool, Sigma Aldrich, St. Louis, MO, USA), liposome KIT (sigma grade, made of lyophilized egg yolk, L4395, Sigma Aldrich, USA), propylene glycol (PG) (PT. Brataco, Indonesia), glycerin (PT. Brataco, Indonesia), tween 80 (Merck, Kenilworth, NJ, USA), phosphate-buffered solution (PBS) (PT. Brataco, Indonesia), potassium bromide (Merck, Kenilworth, NJ, USA), methylparaben (Sigma Aldrich, St. Louis, MO, USA), acetic acid (Sigma Aldrich, St. Louis, MO, USA), benzoic acid (Sigma Aldrich, St. Louis, MO, USA), and sodium benzoate (Sigma Aldrich, St. Louis, MO, USA).

\subsection{Excipient Optimization and Preparation of Film-Forming Solution (Base Solution)}

The selection of polymers between CAS and CWS was based on their sprayability. Here, 5\% PG and 5\% glycerin were used as plasticizers; these were selected based on the 
characteristics of the resulting film. In addition, $2 \%$ tween 80 was used as a surfactant to increase the chitosan solubility and dispersion stability of the hEGF-liposomes, while $0.1 \%$ methylparaben, $0.1 \%$ benzoic acid, and $0.1 \%$ sodium benzoate were used as preservatives; these were selected based on solubility and compatibility between excipients.

The preparation of the base solution was achieved by dissolving CAS in a $0.5 \%$ acetic acid solution, and the CWS in distilled water was then homogenized using a stirrer for $1 \mathrm{~h}$. Each chitosan solution (CAS and CWS) was mixed with tween 80. The plasticizer was added slowly. Then, the preservatives were finally added and stirred until homogeneous.

\subsection{Preparation of hEGF-Liposomes}

The liposome preparation was carried out using the thin-film hydration method. Cholesterol and phospholipids (soy lecithin) were mixed at a 1:1 molar ratio in $6 \mathrm{~mL}$ of chloroform:methanol (1:1). The solvent was then evaporated using a rotavapor at $50{ }^{\circ} \mathrm{C}$. The hEGF solution in a phosphate buffer at $\mathrm{pH} 7.4$ was then added to the dried liposome film with a loading dose of $2 \%$. Then, the hEGF-liposome mixture was mixed until homogeneous at a speed of $3,000 \mathrm{rpm}\left(50^{\circ} \mathrm{C}\right)$ and then sonicated using a bath sonicator (Branson 5200 Ultrasonic, Branson, Brookfield, CT, USA) for 30 min [20].

\subsection{Entrapment Efficiency}

Standard curves were made using hEGF standard solution (1000 ppm) that was diluted to 25, 50, 100, 200, and $400 \mathrm{ppm}$. Each solution was put into the spectrophotometer's microplate in an amount of $100 \mu \mathrm{L}$. The deposition of hEGF-liposome particles was carried out using a high-speed microcentrifugator (Benchmark's MC-12, Benchmark Scientific, Inc., Sayreville, NJ, USA) at a speed of 13,500 rpm for $1 \mathrm{~h}$. The supernatant was separated and then stored in a microplate in an amount of $100 \mu \mathrm{L}$. Bradford reagent was added to the microplate in an amount of $40 \mu \mathrm{L}$ for each standard solution and sample solution. $\mathrm{Ab}$ sorbance measurements of standard and sample solutions were carried out at a wavelength of $595 \mathrm{~nm}$ (Epoch ${ }^{\mathrm{TM}}$ Microplate Spectrophotometer, BioTek Instrument, Inc., Winooski, VT, USA). The concentration of free hEGF in the sample solution was determined using the linear equation of the standard curve. The obtained linear equation can be seen below:

$$
y=5.341 x+0.026
$$

\subsection{Preparation of Film-Forming Spray}

The film-forming spray was prepared by mixing hEGF-liposomes into a base solution to a final hEGF concentration of $75 \mu \mathrm{g} / \mathrm{mL}$ using a mixer at a speed of $1000 \mathrm{rpm}$. After being homogenized, the mixture was sonicated for $30 \mathrm{~min}$ [20,50-52].

\subsection{Measurement of Viscosity and $\mathrm{pH}$}

The viscosity of the base solution was measured using a Brookfield viscometer (NDJ$8 S$ Viscometer, Dongguan Tianjian Machinery Equipment Co., Ltd., Changsha, China). The viscosity data were used to find the value of the limit of the viscosity of the film-forming solution that could be sprayed [53]. The $\mathrm{pH}$ of the solution was measured using a $\mathrm{pH}$ meter (HI 2211 pH/ORP Meter, HANNA Instruments, Woonsocket, RL, USA). Each measurement was made five times.

\subsection{Observation of the hEGF-Liposome FTIR Spectrum}

Interactions between hEGF and liposomes were analyzed using FTIR spectrophotometry (Shimadzu Prestige 21 FTIR spectrophotometer). Here, $200 \mathrm{mg} \mathrm{KBr}$ pellets were used as blanks, and $1 \mathrm{mg}$ of hEGF-liposome film that had been dried at room temperature $\left(25^{\circ} \mathrm{C}\right)$ was analyzed by FTIR at wavelengths of $4000 \mathrm{~cm}^{-1}$ to $400 \mathrm{~cm}^{-1}$. 


\subsection{Determination of the Deacetylation Degree of Chitosan}

The degree of chitosan deacetylation was determined using the FTIR chitosan spectrum by calculating the absorption ratio between a wavelength of $1320 \mathrm{~cm}^{-1}$, which is a typical peak of $\mathrm{OH}, \mathrm{NH}_{2}$, or $\mathrm{CO}$, and a wavelength of $1420 \mathrm{~cm}^{-1}$, as a typical peak of acetyl in chitin [54]. The following equation was used to calculate the deacetylation degree (DD) of chitosan:

$$
\% \mathrm{DD}=100-\frac{\frac{\mathrm{A}_{1320}}{\mathrm{~A}_{1420}}-0.3822}{0.03133}
$$

\subsection{Determination of Particle Size, Polydispersity Index, and Zeta Potential}

The determination of particle size, polydispersity index, and potential zeta of blank liposomes and hEGF-liposomes were carried out using a particle size analyzer (Horiba SZ-100, Horiba Ltd., Kyoto, Japan). The test was carried out by dispersing the sample in a phosphate buffer at $\mathrm{pH}$ 6.8, after which $1 \mathrm{~mL}$ was taken for testing [55].

\subsection{Observation of hEGF-Liposome Surface Morphology and TEM Analysis}

The lecithin-cholesterol film formed was observed using a digital microscope (M87041000, Chongqing Dontop Optics Co., Ltd, Chongqing, China) at $1000 \times$ magnification to observe the differences in surface morphology of the liposome film before and after being hydrated. Transmission electron microscopy (TEM) (HITACHI HT7700, Hitachi Ltd., Tokyo, Japan) was also used to observe the shape and successful coating of the liposome. We added $1 \%$ phosphotungstic acid ( $\mathrm{pH}$ 6.0) to the sample, and then one drop was placed onto a carbon-coated copper grid. Samples were dried at room temperature, and then the surface morphology was observed.

\subsection{Occlusion Potential of Film}

This test was performed by covering the mouth of the glass beaker containing $50 \mathrm{~mL}$ of water with filter paper. One of the papers was sprayed with a film-forming solution and allowed to form a film. The glass beaker was then stored at room temperature and humidity. The permeability of the film to water was determined based on the reduced water weight in the beaker glass [29]. The assessment was determined using the following formula:

$$
\mathrm{F}=\frac{\mathrm{A}-\mathrm{B}}{\mathrm{A}} \times 100
$$

where $\mathrm{F}$ is the occlusivity factor, $\mathrm{A}$ is the reduced water weight in the glass beaker with filter paper without film, and B is the reduced water weight in the beaker glass with a film-coated filter paper.

\subsection{Spray Angle, Pattern, and Droplet Size Distribution}

Water-sensitive paper was used to obtain a clear pattern down to the size distribution of the spray droplets. The nozzle used was an ordinal spray nozzle [22]. The diameter of the fixed pattern was then measured to determine the spray angle. Five repetitions of measurements were taken.

$$
\text { Spray angle }(\theta)=\tan ^{-1}\left(\frac{1}{\mathrm{r}}\right)
$$

where 1 is the distance of the paper surface from the nozzle, and $r$ is the radius of the circle. The spray spacing that is generally used is $15 \mathrm{~cm}$ [56]. The droplet size distribution was determined using ImageJ software (version 1.53e). The spray-pattern image was converted to a binary image, and then the average droplet size $(\mu \mathrm{m})$ was measured.

\subsection{Uniformity of Weight per Spray}

The uniformity of weight per spray was determined by measuring the weight of each spray [29]. Spray weight was weighed at spray 5, 10, 20, 30, and 50 to determine 
the uniformity and repeatability of the dose [57]. In this test, the pressure applied on the sprayer was not controlled for mimicking the real usage.

\subsection{Drying Shrinkage of the Film}

This test was carried out to determine the reduction in weight during the drying process of the film. Several volume variations of the film-forming solution $(1,2.5,5,10$, and $15 \mathrm{~mL}$ ) were dried on a petri dish to obtain a linear equation:

$$
\mathrm{y}=0.971 \mathrm{x}+0.0335
$$

\subsection{Theoritical Film Thickness}

The film thickness was calculated using the following equation (ASTM E0252-06R13 standard):

$$
\text { Thickness }(\mathrm{cm})=\frac{\text { Mass }(\mathrm{g})}{\text { Area }\left(\mathrm{cm}^{2}\right) \times \text { Density }\left(\mathrm{g} / \mathrm{cm}^{3}\right)}
$$

\subsection{Stability Test}

The preparations were stored in a climatic chamber at a temperature of $40 \pm 2{ }^{\circ} \mathrm{C}$ and RH $75 \pm 5 \%$ according to the conditions of the IVB zone. Preparations were stored for 1 month, and changes in $\mathrm{pH}$ and viscosity were observed on days $0,1,7,14$, and 28 . The particle size of the hEGF-liposomes was again tested to observe changes in particle size and distribution on the final day of observation.

\subsection{In Vivo Study}

\subsubsection{Animal Preparation}

The inclusion criteria for the animals were male mice of the Swiss Webster strain aged 6-8 weeks with a body weight of 20-30 g, that were active and healthy during the adaptation period. The exclusion criteria were mice that were sick during adaptation, or had an infection or died during treatment [58]. Prior to testing, mice were acclimatized for 1 week before the experiment, with daily feeding and drinking and cleaning of cages twice a week on a regular basis. The population of test animals per group was calculated using the Frederer equation [59]. Based on this equation, the number of mice used was 24, with a number of mice per group of 4 mice. All experiments were performed following the guidelines of OIE animal welfare standards and were approved by the local Ethical Committee Faculty of Medicine, Universitas Padjadjaran, Bandung (No:1296/UN6.C10/PN2017).

\subsubsection{Animal Grouping and Wound Making}

Mice were anesthetized with ketamine $40 \mathrm{mg} / \mathrm{Kg}$ BW intramuscularly, then placed on a surgical tub in the prone position. The hair around the middle back of the mice was shaved, then cleaned with alcohol-soaked cotton. The wound was made in a circular form with a diameter of $4 \mathrm{~mm}$ using a punch biopsy. The test animals were then grouped and marked as follows:

Group I: negative control (without any treatment);

Group II: given the water-soluble chitosan base solution;

Group III: given hEGF KIT solution (dose $75 \mu \mathrm{g}$ );

Group IV: given recombinant hEGF solution (dose $75 \mu \mathrm{g}$ );

Group V: given hEGF-liposome suspension (dose $75 \mu \mathrm{g}$ );

Group VI: given FFSWSC containing hEGF-liposomes (dose $75 \mu \mathrm{g}$ ).

Groups II-VI were given the treatment at intervals of 2 days. Administration of the preparation at intervals of 2 days aimed to observe the effect of controlled release of the chitosan film matrix on the effectiveness of hEGF. The wound area was observed digitally using a camera (Canon EOS 1200D), and the wound area was calculated by ImageJ software until the wound was completely closed. 


\subsection{Statistical Analysis}

The data were statistically analyzed using the Statistical Package for the Social Sciences (SPSS) version 22 (IBM Corporation, New York, NY, USA). The correlation between the variables of the dosage characteristics was analyzed using the Pearson correlation test, while the multiple comparison analysis in the in vivo test was carried out using a post hoc Games-Howell test for day 4 and a Bonferroni test for days 6 and 8.

\section{Conclusions}

The hydration film method produced hEGF-liposomes that were round and spread with a Z-average of $219.3 \mathrm{~nm}$, whereas the film-forming solution, which provided good sprayability, was the formula containing $2 \%$ water-soluble chitosan and $3 \%$ propylene glycol, with viscosity, spray angle, droplet size, spray weight, and occlusion factor of $21.94 \pm 0.05$ mPa.s, $73.03 \pm 1.28^{\circ}, 54.25 \pm 13.33 \mu \mathrm{m}, 0.14 \pm 0.00 \mathrm{~g}$, and $14.57 \pm 3.41 \%$, respectively. The FFSWSC containing hEGF-liposomes was stable during storage for a month in an IVB zone condition. A wound healing activity test on mice showed that hEGF-liposomes in FFSWSC accelerated wound closure significantly, with a complete wound closure on day 6. Based on the findings, we concluded that FFSWSC containing hEGF-liposomes has the potential to be used as a wound dressing.

Author Contributions: Conceptualization, A.K.U. and S.S.; data curation, A.K.U., S.S., I.P.M., and N.W.; formal analysis, A.K.U., S.S., I.P.M., and N.W.; funding acquisition, S.S. and I.P.M.; investigation, A.K.U.; methodology, A.K.U. and N.W.; project administration, A.K.U., S.S., I.P.M., and N.W.; resources, A.K.U., S.S., I.P.M., and N.W.; software, A.K.U.; supervision, A.K.U., S.S., and N.W.; validation, A.K.U., S.S., I.P.M., and N.W.; visualization, A.K.U.; writing-original draft, A.K.U.; writing-review and editing, A.K.U. All authors have read and agreed to the published version of the manuscript.

Funding: This work was supported by research grants from the Ministry of Research and Technology/National Research and Innovation Agency (1827/UN6.3.1/LT/2020).

Institutional Review Board Statement: All experiments were performed following the guidelines of OIE animal welfare standards and were approved by the local Ethical Committee Faculty of Medicine, Universitas Padjadjaran, Bandung (No:1296/UN6.C10/PN2017).

Informed Consent Statement: Not applicable.

Data Availability Statement: Not applicable.

Conflicts of Interest: The authors declare no conflict of interest. The funders had no role in the design of the study; in the collection, analyses, or interpretation of data; in the writing of the manuscript; or in the decision to publish the results.

Sample Availability: Lyophilized hEGF is available from the authors.

$\begin{array}{ll}\text { Abbreviations } \\ \text { CAS } & \text { Acid-soluble chitosan } \\ \text { CWS } & \text { Water-soluble chitosan } \\ \text { DD } & \text { Deacetylation degree } \\ \text { DFU } & \text { Diabetic foot ulcer } \\ \text { GFs } & \text { Growth factors } \\ \text { hEGF } & \text { Human epidermal growth factor } \\ \text { PDI } & \text { Polydispersity index } \\ \text { PG } & \text { Propylene glycol } \\ \text { WVP } & \text { Water vapor permeability } \\ \text { FFS } & \text { Film-forming spray } \\ \text { FFSWSC } & \text { Film-forming spray of water-soluble chitosan }\end{array}$




\section{References}

1. Martí-Carvajal, A.J.; Gluud, C.; Nicola, S.; Simancas-Racines, D.; Reveiz, L.; Oliva, P.; Cedeño-Taborda, J. Growth factors for treating diabetic foot ulcers. Cochrane Database Syst. Rev. 2015, 28. [CrossRef]

2. Sridharan, K.; Sivaramakrishnan, G. Growth factors for diabetic foot ulcers: Mixed treatment comparison analysis of randomized clinical trials. Br. J. Clin. Pharmacol. 2018, 84, 434-444. [CrossRef]

3. Park, J.W.; Hwang, S.R.; Yoon, I.-S. Advanced Growth Factor Delivery Systems in Wound Management and Skin Regeneration. Molecules 2017, 22, 1259. [CrossRef]

4. Gainza, G.; Pastor, M.; Aguirre, J.J.; Villullas, S.; Pedraz, J.L.; Hernandez, R.M.; Igartua, M. A novel strategy for the treatment of chronic wounds based on the topical administration of rhEGF-loaded lipid nanoparticles: In vitro bioactivity and in vivo effectiveness in healing-impaired db/db mice. J. Control. Release 2014, 185, 51-61. [CrossRef]

5. Griol-Charhbili, V.; Fassot, C.; Messaoudi, S.; Perret, C.; Agrapart, V.; Jaisser, F. Epidermal Growth Factor Receptor Mediates the Vascular Dysfunction But Not the Remodeling Induced by Aldosterone/Salt. Hypertension 2011, 57, 238-244. [CrossRef]

6. Singla, S.; Singla, S.; Kumar, A.; Singla, M. Role of Epidermal Growth Factor in Healing of Diabetic Foot Ulcers. Indian J. Surg. 2012, 74, 451-455. [CrossRef] [PubMed]

7. Tsang, M.W.; Wong, W.K.R.; Hung, C.S.; Lai, K.-M.; Tang, W.; Cheung, E.Y.; Kam, G.; Leung, L.; Chan, C.W.; Chu, C.M.; et al. Human Epidermal Growth Factor Enhances Healing of Diabetic Foot Ulcers. Diabetes Care 2003, 26, 1856-1861. [CrossRef] [PubMed]

8. Berlanga-Acosta, J.; Fernández-Montequín, J.; Valdés-Pérez, C.; Savigne-Gutiérrez, W.; Mendoza-Marí, Y.; García-Ojalvo, A.; Falcón-Cama, V.; Del Barco-Herrera, D.G.; Fernández-Mayola, M.; Pérez-Saad, H.; et al. Diabetic Foot Ulcers and Epidermal Growth Factor: Revisiting the Local Delivery Route for a Successful Outcome. BioMed Res. Int. 2017, 2017, 1-10. [CrossRef]

9. Bozzuto, G.; Molinari, A. Liposomes as nanomedical devices. Int. J. Nanomed. 2015, 10, 975-999. [CrossRef] [PubMed]

10. Mahmoudi, R.; Ardakani, M.T.; Verdom, B.H.; Bagheri, A.; Mohammad-Beigi, H.; Aliakbari, F.; Salehpour, Z.; Alipour, M.; Afrouz, S.; Bardania, H. Chitosan nanoparticles containing Physalis alkekengi-L extract: Preparation, optimization and their antioxidant activity. Bull. Mater. Sci. 2019, 42, 131. [CrossRef]

11. Bardania, H.; Shojaosadati, S.A.; Kobarfard, F.; Morshedi, D.; Aliakbari, F.; Tahoori, M.T.; Roshani, E. RGD-Modified NanoLiposomes Encapsulated Eptifibatide with Proper Hemocompatibility and Cytotoxicity Effect. Iran. J. Biotechnol. 2019, 17, 8-13. [CrossRef]

12. Mahmoudi, R.; Mirahmadi-Babaheidri, S.A.; Delaviz, H.; Fouani, M.H.; Alipour, M.; Barmak, M.J.; Christiansen, G.; Bardania, H. RGD peptide-mediated liposomal curcumin targeted delivery to breast cancer cells. J. Biomater. Appl. 2020, 35, 743-753. [CrossRef] [PubMed]

13. Mahmoudi, R.; Hassandokht, F.; Ardakani, M.T.; Karimi, B.; Roustazadeh, A.; Tarvirdipour, S.; Barmak, M.J.; Nikseresht, M.; Baneshi, M.; Mousavizadeh, A.; et al. Intercalation of curcumin into liposomal chemotherapeutic agent augments apoptosis in breast cancer cells. J. Biomater. Appl. 2020, 35, 1005-1018. [CrossRef] [PubMed]

14. Alemdaroğlu, C.; Değim, Z.; Çelebi, N.; Zor, F.; Öztürk, S.; Erdoǧan, D. An investigation on burn wound healing in rats with chitosan gel formulation containing epidermal growth factor. Burns 2006, 32, 319-327. [CrossRef] [PubMed]

15. Parchen, G.P.; Jacumazo, J.; Koop, H.S.; Biscaia, S.M.P.; Trindade, E.S.; Silveira, J.L.M.; de Freitas, R.A. Modulation of Epidermal Growth Factor Release by Biopolymer-Coated Liposomes. J. Pharm. Sci. 2020, 109, 2294-2301. [CrossRef]

16. Prats, P.; Duconge, J.; Valenzuela, C.; Berlanga, J.; Edrosa, C.; Fernández-Sánchez, E. Disposition and receptor-site binding of125I-EGF after topical administration to skin wounds. Biopharm. Drug Dispos. 2002, 23, 67-76. [CrossRef] [PubMed]

17. Mandal, U.K.; Chatterjee, B.; Pauzi, F.H.B. A Review on Transdermal Spray: Formulation Aspect. Mathews J. Pharm. Sci. 2016, 2, 006.

18. Ibrahim, S.A. Spray-on transdermal drug delivery systems. Expert Opin. Drug Deliv. 2014, 12, 195-205. [CrossRef] [PubMed]

19. Kahya, N. Water Soluble Chitosan Derivatives and their Biological Activities: A Review. Polym. Sci. 2019, 5, 1-16. [CrossRef]

20. Değim, Z.; Çelebi, N.; Alemdaroğlu, C.; Deveci, M.; Öztürk, S.; Özoğul, C. Evaluation of chitosan gel containing liposome-loaded epidermal growth factor on burn wound healing. Int. Wound J. 2011, 8, 343-354. [CrossRef]

21. Rachtanapun, P.; Jakkaew, M.; Suriyatem, R. Characterization of Chitosan and Carboxymethyl Chitosan Films from Various Sources and Molecular Sizes. Adv. Mater. Res. 2012, 506, 417-420. [CrossRef]

22. Umar, A.K.; Butarbutar, M.E.T.; Sriwidodo, S.; Wathoni, N. Film-Forming Sprays for Topical Drug Delivery. Drug Des. Dev. Ther. 2020, 14, 2909-2925. [CrossRef] [PubMed]

23. Oliveira, A.C.; Coelho, M.G.; Pires, R.F.; Franco, M.R. Solubility of Benzoic Acid in Mixed Solvents. J. Chem. Eng. Data 2007, 52, 298-300. [CrossRef]

24. Blaug, S.M.; Ahsan, S.S. Interaction of Parabens with Nonionic Macromolecules. J. Pharm. Sci. 1961, 50, 441-443. [CrossRef]

25. Blanchard, J. Effect of Polyols on Interaction of Paraben Preservatives with Polysorbate 80. J. Pharm. Sci. 1980, 69, 169-173. [CrossRef]

26. Patel, N.K.; Kostenbauder, H.B. Interaction of Preservatives with Macromolecules I. J. Pharm. Sci. 1958, 47, 289-293. [CrossRef]

27. Yati, K.; Srifiana, Y.; Putra, F. Effect of optimization of Tween 80 and propylene glycol as a surfactant and cosurfactant on the physical properties of aspirin microemulsion. Int. J. Appl. Pharm. 2017, 30, 127. [CrossRef]

28. Shashidhar, G.M.; Manohar, B. Nanocharacterization of liposomes for the encapsulation of water soluble compounds from Cordyceps sinensis CS1197 by a supercritical gas anti-solvent technique. RSC Adv. 2018, 8, 34634-34649. [CrossRef] 
29. Ranade, S.; Bajaj, A.; Londhe, V.; Babul, N.; Kao, D. Fabrication of topical metered dose film forming sprays for pain management. Eur. J. Pharm. Sci. 2017, 100, 132-141. [CrossRef]

30. Lombardo, D.; Calandra, P.; Barreca, D.; Magazù, S.; Kiselev, M.A. Soft Interaction in Liposome Nanocarriers for Therapeutic Drug Delivery. Nanomaterials 2016, 6, 125. [CrossRef]

31. Yokota, D.; Moraes, M.; Pinho, S. Characterization of lyophilized liposomes produced with non-purified soy lecithin: A case study of casein hydrolysate microencapsulation. Braz. J. Chem. Eng. 2012, 29, 325-335. [CrossRef]

32. Nunthanid, J.; Puttipipatkhachorn, S.; Yamamoto, K.; Peck, G.E. Physical Properties and Molecular Behavior of Chitosan Films. Drug Dev. Ind. Pharm. 2001, 27, 143-157. [CrossRef]

33. Danaei, M.; Dehghankhold, M.; Ataei, S.; Davarani, F.H.; Javanmard, R.; Dokhani, A.; Khorasani, S.; Mozafari, M.R. Impact of Particle Size and Polydispersity Index on the Clinical Applications of Lipidic Nanocarrier Systems. Pharmaceutics 2018, 10, 57. [CrossRef]

34. Caputo, F.; Clogston, J.; Calzolai, L.; Rösslein, M.; Prina-Mello, A. Measuring particle size distribution of nanoparticle enabled medicinal products, the joint view of EUNCL and NCI-NCL. A step by step approach combining orthogonal measurements with increasing complexity. J. Control. Release 2019, 299, 31-43. [CrossRef]

35. Kumar, A.; Dixit, C.K. Methods for characterization of nanoparticles. In Advances in Nanomedicine for the Delivery of Therapeutic Nucleic Acids; Elsevier: Leiden, The Netherlands, 2017; pp. 43-58.

36. Yadav, D.; Sandeep, K.; Pandey, D.; Dutta, R.K. Liposomes for Drug Delivery. J. Biotechnol. Biomater. 2017, 7, 4. [CrossRef]

37. Zhuang, C.; Zhong, Y.; Zhao, Y. Effect of deacetylation degree on properties of Chitosan films using electrostatic spraying technique. Food Control. 2018, 97, 25-31. [CrossRef]

38. Gohel, M.C.; Nagori, S.A. Fabrication of Modified Transport Fluconazole Transdermal Spray Containing Ethyl Cellulose and Eudragit@RS100 as Film Formers. AAPS PharmSciTech 2009, 10, 684-691. [CrossRef] [PubMed]

39. Paradkar, M.; Thakkar, V.; Soni, T.; Gandhi, T.; Gohel, M. Formulation and evaluation of clotrimazole transdermal spray. Drug Dev. Ind Pharm. 2015, 41, 1718-1725. [CrossRef]

40. Maksum, I.P.; Rostinawati, T.; Subroto, T. Extracellular secretion recombinant of human epidermal growth factor (hEGF) using pectate lyase B (PelB) signal peptide in escherichia coli BL21(DE3). Int. J. Res. Pharm. Sci. 2017, 8, 33-40.

41. Torres, M.A. Viscous and Viscoelastic Properties of Chitosan Solutions and Gels. Response 2006, 9, 101-108.

42. Cho, J.; Heuzey, M.-C.; Bégin, A.; Carreau, P.J. Viscoelastic properties of chitosan solutions: Effect of concentration and ionic strength. J. Food Eng. 2006, 74, 500-515. [CrossRef]

43. Budai, L.; Szabadi, E.; Hajdú, M.; Budai, M.; Klebovich, I.; Antal, I. The influence of selected excipients on the rheological behaviour of chitosan based ocular pharmaceutical systems. J. Phys. Conf. Ser. 2015, 602, 012041. [CrossRef]

44. Suyatama, N.E.; Tighzert, L.; Copinet, A. Effects of Hydrophilic Plasticizers on Mechanical, Thermal, and Surface Properties of Chitosan Films. J. Agric. Food Chem. 2005, 53, 3950-3957. [CrossRef]

45. Yeh, M.-K.; Chang, W.-K.; Tai, Y.-J.; Chiang, C.-H.; Hu, C.-S.; Hong, P.-D. The comparison of protein-entrapped liposomes and lipoparticles: Preparation, characterization, and efficacy of cellular uptake. Int. J. Nanomed. 2011, 6, 2403-2417. [CrossRef] [PubMed]

46. Carugo, D.; Bottaro, E.; Owen, J.; Stride, E.; Nastruzzi, C. Liposome production by microfluidics: Potential and limiting factors. Sci. Rep. 2016, 6, 25876. [CrossRef]

47. Foteini, P.; Pippa, N.; Naziris, N.; Demetzos, C. Physicochemical study of the protein-liposome interactions: Influence of liposome composition and concentration on protein binding. J. Liposome Res. 2019, 29, 313-321. [CrossRef]

48. Sabın, J.; Prieto, G.; Ruso, J.M.; Hidalgo-Alvarez, R.; Sarmiento, F.; Sabin, J. Size and stability of liposomes: A possible role of hydration and osmotic forces. Eur. Phys. J. E 2006, 20, 401-408. [CrossRef] [PubMed]

49. Wolfram, J.; Suri, K.; Yang, Y.; Shen, J.; Celia, C.; Fresta, M.; Zhao, Y.; Shen, H.; Ferrari, M. Shrinkage of pegylated and non-pegylated liposomes in serum. Colloids Surf. B Biointerfaces 2014, 114, 294-300. [CrossRef] [PubMed]

50. Carnwath, R.; Graham, E.; Reynolds, K.; Pollock, P. The antimicrobial activity of honey against common equine wound bacterial isolates. Veter J. 2014, 199, 110-114. [CrossRef]

51. Al-Niaimi, F.; Chiang, N.Y.Z. Topical Vitamin C and the Skin: Mechanisms of Action and Clinical Applications. J. Clin. Aesthetic Dermatol. 2017, 10, 14-17.

52. Vollmer, D.L.; West, V.A.; Lephart, E.D. Enhancing Skin Health: By Oral Administration of Natural Compounds and Minerals with Implications to the Dermal Microbiome. Int. J. Mol. Sci. 2018, 19, 3059. [CrossRef] [PubMed]

53. Geh, K.; Stelzl, A.; Gröne, A.; Wagner, L.; Förster, B.; Winter, G. Development of a sprayable hydrogel formulation for the skin application of therapeutic antibodies. Eur. J. Pharm. Biopharm. 2019, 142, 123-132. [CrossRef]

54. Brugnerotto, J.; Lizardi, J.; Goycoolea, F.M.; Argüelles-Monal, W.; Desbrières, J.; Rinaudo, M. An infrared investigation in relation with chitin and chitosan characterization. Polymer 2001, 42, 3569-3580. [CrossRef]

55. Rachmawati, A.L.; Surini, S. Formulasi dan Karakterisasi Nanopartikel Sambungsilang Gom Xantan dan Gom Akasia Untuk Penghantaran Insulin Oral. Pharm. Sci. Res. 2018, 5, 159-168.

56. Gohli, T.; Shah, P. Formulation and Development of Transdermal Spray of Ibandronate Sodium. Int. J. Pharm. Pharm. Res. 2019, $16,46-58$.

57. Lu, W.; Luo, H.; Wu, Y.; Zhu, Z.; Wang, H. Preparation and characterization of a metered dose transdermal spray for testosterone. Acta Pharm. Sin. B 2013, 3, 392-399. [CrossRef] 
58. Hidayat, F.K.; Elfiah, U.; Sofiana, K.D. Perbandingan Jumlah Makrofag pada Luka Insisi Full Thickness antara Pemberian Ekstrak Umbi Bidara Upas dengan $\mathrm{NaCl}$ pada Tikus Wistar Jantan (Comparison of The Number of Macrophage in Full Thickness Wound Incision between Merremia mammosa Extract Treatment and $\mathrm{NaCl}$ in Male Wistar Rats). J. AMS 2015, 1,9-13.

59. Federer, W.T. Randomization and Sample Size in Experimentation. Food Drug Adm. Stat. Semin. 1966, 1-14. 